\title{
Effect of CD133 overexpression on bone metastasis in prostate cancer cell line LNCaP
}

\author{
HONG MOON SOHN ${ }^{1,2^{*}}$, BORA KIM ${ }^{1,2^{*}}$, MINEON PARK ${ }^{1,2}$, YOUNG JONG KO ${ }^{1,2}$, YEON HEE MOON ${ }^{3}$, \\ JAE MYUNG SUN ${ }^{4}$, BYUNG-CHEOL JEONG ${ }^{1,2}$, YOUNG WOOK KIM ${ }^{1,2}$ and WONBONG LIM ${ }^{1,2,4}$ \\ ${ }^{1}$ Department of Orthopaedic Surgery; ${ }^{2}$ Laboratory of Orthopaedic Research, Chosun University Hospital, Dong-
Gu, Gwangju 61453; ${ }^{3}$ Department of Dental Hygiene, Chodang University, Muan County, Jeollanam-do 58530;
${ }^{4}$ Department of Medicine, College of Medicine, Chosun University, Dong-gu, Gwangju 61452, Republic of Korea
}

Received September 27, 2018; Accepted May 10, 2019

DOI: $10.3892 / 01.2019 .10443$

\begin{abstract}
Prostate cancer (PC) metastasizes to the bone, and a small number of cancer cells, described as cancer stem cells (CSCs), have the ability to differentiate into tumor cells. CSCs are responsible for tumor recurrence and metastases. In the present study, we examined whether ectopic overexpression of CD133, a key molecule maintaining the stability of CSCs in the human PC cell line, $\mathrm{LnCaP}$, caused bone metastasis in a mouse model. Ectopic overexpression of CD133 was induced in LnCaP cells, and CSC-related protein expression was measured. Furthermore, a colony-forming assay was performed to compare results against the blank green fluorescent protein-expressing cells. Furthermore, epithelial to mesenchymal transition-related protein expression, cell migration and wound healing were investigated. To assess the role of CD133 in bone metastasis, CD133-overexpressing $\mathrm{LnCaP}$ cells were inoculated into mice via intracardiac injection, and bone metastasis was assessed via histological and immunohistochemical study. In addition, cytokine arrays were used to determine the cytokines involved in bone metastasis. Ectopic overexpression of CD133 in $\mathrm{LnCaP}$ cells increased CSC properties such as Oct-4 and Nanog expression and colony-forming ability. Furthermore, epithelial-to-mesenchymal transition (EMT) properties, including decreased E-cadherin and increased vimentin expression, wound gap distance, and cell migration increased. CD133 overexpression led to formation of bone metastatic
\end{abstract}

Correspondence to: Professor Wonbong Lim, Department of Medicine, College of Medicine, Chosun University, 309 Philmundaero, Dong-Gu, Gwangju, Gyeonggi 61452, Republic of Korea

E-mail:wonbong@chosun.ac.kr

*Contributed equally

Abbreviations: PC, prostate cancer; MIF, macrophage migration inhibitory factor; CSC, cancer stem cell; EMT, epithelial-to-mesenchymal transition; TCF-4, anti-transcription factor 4

Key words: CD133, CSC, bone metastasis, MIF, osteolysis tumors in mice, consistent with results of hematoxylin and eosin staining. In addition, an increase in expression of the macrophage-migration inhibitory factor was observed at the tumor margin in mice inoculated with $\mathrm{CD} 133^{+} \mathrm{LNCaP}$ cells. These findings suggest a regulatory role of CD133 in stem cell and EMT properties, and the sustained acquisition of osteolytic features in PC. Therefore, our results may facilitate development of a novel classification system and therapeutic strategies for bone metastasis of PC.

\section{Introduction}

Prostate cancer (PC) is the most commonly diagnosed form of cancer and the sixth leading cause of cancer-related deaths among men worldwide (1). The 5-year survival rate is approximately $100 \%$ in patients with localized PC, but it drops to $31 \%$ in those with distant metastasis (2). Similar to most other solid malignancies, PC may metastasize to distant organs such as the liver, lungs, and brain; however, it has an abnormally high propensity to metastasize to bones (3). Thus, it is desirable to gain a better understanding of mechanisms underlying PC metastasis to the bone for development and use of therapies to improve patient survival.

Studies have provided new insights into this advanced disease based on critical molecular and cellular events surrounding tumor progression, invasion, and metastasis to the bone and other sites (4). Epithelial-to-mesenchymal transition (EMT), in which cellular, morphological, and functional switches may transform adherent epithelial cells to migratory mesenchymal cells, is critical for tumorigenic progression and cancer metastasis. EMT may promote stem cell-related properties and generate cells with features related to tumor initiation (5). During EMT, tumor cells exhibit stem cell characteristics and confer invasive and migratory properties to primary tumor cells, ultimately resulting in metastasis (5).

It is hypothesized that tumors rely on a small portion of cells called cancer stem cells (CSCs) that have the ability to self-renew and generate multiple 'mature' tumor progenies (6). CSCs are typically dormant, and their regrowth is responsible for metastases (7). Primary tumors comprise a majority of differentiated epithelial cells and a small number of cells expressing stem cell markers (i.e., PC stem cells) (8). 
A previous study showed that CSCs derived from primary tumors exhibited increased invasion, self-renewal, and clonogenic properties (9). These cells may be identified using several CSC markers such as CD133, c-Met, and prostate stem cell antigens (10). A recent analysis involving a cohort of high-risk PC patients showed that the number of positive cancer cells for the a-6 and a-2 integrin subunits and the c-Met receptor in primary PC correlated with bone metastatic progression (11).

CD133 (prominin-1), a 5-transmembrane glycoprotein, was originally recognized as a hematopoietic stem cell marker (12). CD133 is regarded as an important cell surface marker used to identify cancer-initiating cell subpopulations in brain tumors, colon carcinoma, head and neck cancer, hepatocellular carcinoma, thyroid carcinoma, and prostate carcinoma $(13,14)$. Previous experiments have demonstrated a correlation between upregulated CD133 expression and progression of EMT in head and neck cancer cells and head and neck squamous cell carcinoma tissues (15). The CD133-mediated molecular mechanisms regulating cancer-initiating cells in bone metastasis of PC remain unclear.

In the present study, we have demonstrated that CD133 plays a significant role by increasing stemness, enhancing EMT, and promoting bone metastasis in a PC cell line, LNCaP. Furthermore, we aimed to identify cytokines secreted by $\mathrm{CD} 133+\mathrm{LNCaP}$ cells that play a critical role during bone metastasis of PC cells. Our results suggest that CD133+ PC cells play a central role in bone metastasis.

\section{Materials and methods}

Cell culture. LNCaP and 293T cells were purchased from the Korean Cell Line Bank (KCLB; no. 21573), Korean Cell Line Research Foundation, Seoul, Korea, in 2017. The cells were maintained in RPMI-1640 (Welgene, Daegu, Korea) supplemented with $10 \%$ heat-inactivated fetal bovine serum (FBS; Gibco; Thermo Fisher Scientific, Inc., Waltham, MA, USA) and $0.1 \%$ antibiotic/antimycotic solution (Welgene) at $37^{\circ} \mathrm{C}$ in a $5 \% \mathrm{CO}_{2}$ humidified chamber.

Cloning of human CD133 and establishment of stably transfected LNCaPVec control and LNCap ${ }^{C D 133+}$ cells. HT29 colon cancer cells were used as a source of CD133. Cloning of CD133 was performed as previously described (15). Plasmid pcDNA3.1/N-terminal green fluorescent protein (NT-GFP) lacking the CD133 insert was used as a transfection control. 293 T cells were used as a positive control to evaluate the translated fusion product.

Stable cell lines overexpressing the CD133 protein were obtained throughco-transfection of confluentLNCaP-luciferase cells in 100-mm plates with $20 \mu \mathrm{g}$ pcDNA3.1/NT-GFP:CD133 or pcDNA3.1/NT-GFP plasmid using the FuGENE HD transfection reagent, as previously described (15).

Western blot analysis. After reaching approximately $80 \%$ confluency, the medium was removed, and the cells were washed twice with phosphate-buffered saline (PBS, $\mathrm{pH} 7.4$ ). Cell lysates were prepared in $200 \mu \mathrm{l}$ cold lysis buffer [ $1 \%$ NP-40, 50 mM Tris-HCl, pH 7.5, $150 \mathrm{mM}$ sodium chloride $(\mathrm{NaCl}), 0.02 \%$ sodium azide, $150 \mathrm{mg} / \mathrm{ml}$ of phenylmethylsulfonyl fluoride (PMSF), $2 \mathrm{mg} / \mathrm{ml}$ of aprotinin, $20 \mathrm{mg} / \mathrm{ml}$ of leupeptin, and $1 \mathrm{mg} / \mathrm{ml}$ of pepstatin A]. Approximately $30 \mathrm{mg}$ of tissue lysate was separated via $10 \%$ sodium dodecyl sulfate-polyacrylamide gel electrophoresis (SDS-PAGE) and transferred onto a polyvinylidene difluoride (PVDF) membrane (Amersham, Piscataway, NJ, USA). Each membrane was blocked for $30 \mathrm{~min}$ with a blocking solution containing $5 \%$ skim milk in Tris-buffered saline containing Tween-20 (TBST, 2.42 g/l Tris-HCl, 8 g/l NaCl, 0.1\% Tween-20, pH 7.6) and rinsed with TBST. The membrane was incubated overnight at $4^{\circ} \mathrm{C}$ with appropriate primary antibodies, including anti-CD133 (1:1,000; cat. no. MBS850595; MyBioSource, San Diego, CA, USA), anti-octamer-binding transcription factor 4 (Oct-4, 1:1,000; cat. no. 2750, Cell Signaling Technology, Beverly, MA, USA), anti-NANOG (1:1,000; cat. no. 3580; Cell Signaling Technology), anti-(sex determining region Y)-box 2 (SOX2, 1:1,000; cat. no. 2748; Cell Signaling Technology), anti-E-cadherin $(1: 1,000$; cat. no. sc-8426; Santa-Cruz Biotechnology Inc., Dallas, TX, USA), anti-transcription factor 4 (TCF-4, 1:1,000; cat. no. 2953; Cell Signaling Technology), anti-vimentin $(1: 1,000$; cat. no. sc-6260; Santa-Cruz Biotechnology Inc.), anti- $\beta$-catenin (1:1,000; cat. no. 9562; Cell Signaling Technology), and anti-macrophage migration inhibitory factor (MIF, 1:1,000; cat. no. 88186; Cell Signaling Technology). A mouse monoclonal immunoglobulin $\mathrm{G}$ (IgG) specific for glyceraldehyde-3-phosphate dehydrogenase (GAPDH, 1:1,000; cat. no. sc-47724; Santa-Cruz Biotechnology Inc.) was used as a control. The membrane was rinsed with TBST, and protein immunoreactivity was detected using an enhanced chemiluminescence detection kit (ECL, Amersham).

Confocal microscopic analyses. Immunolabeled cells were counterstained with 4',6-diamidino-2-phenylindole (DAPI) provided in ProLong Gold antifade mounting medium (Invitrogen; Thermo Fisher Scientific, Inc., Waltham, MA, USA) to visualize nuclear morphology. Digital images were acquired at the Korea Basic Science Institute Gwangju Center using a TCS SP5 AOBS laser-scanning confocal microscope (Leica Microsystems, Heidelberg, Germany).

Colony-forming assays. Cells were seeded at a density of 1,000 cells/well in non-adherent 24-well culture plates coated with a $10 \%$ poly (2-hydroxyethyl methacrylate) (polyHEMA) solution (Sigma-Aldrich; Merck KGaA, Darmstadt, Germany) in absolute ethanol and then dried overnight. After seeding, cells were incubated in serum-free Dulbecco's modified Eagle's medium (DMEM) supplemented with $200 \mathrm{ng} / \mathrm{ml}$ epidermal growth factor (Sigma-Aldrich; Merck KGaA), $20 \mathrm{ng} / \mathrm{ml}$ of basic fibroblast growth factor (Sigma-Aldrich; Merck KGaA), and B-27 supplement (Invitrogen; Thermo Fisher Scientific, Inc.). After 5 days of incubation, the number of spheroids in each well was counted using a light microscope (Zeiss, Zena, Germany).

Cell migration assay. Cells were seeded at $1 \times 10^{5}$ cells/well in 6-well plates and cultured to approximately $90 \%$ confluency in $1 \mathrm{ml}$ of DMEM supplemented with $10 \% \mathrm{FBS}$. The media were removed from the wells, and a straight transverse line was drawn through the adherent cells using a ruler and sterile $200-\mu 1$ plastic micropipette tip to produce a uniform gap. Serum-free DMEM was added, and the distance between 
the gaps was measured immediately and $24 \mathrm{~h}$ later, following image capture of six random microscopic fields. The distance measured immediately was defined as $100 \%$.

Cell invasion assay. Cell invasion was assessed using a chemotaxis chamber (Neuro Probe, Gaithersburg, MD, USA). The cells $\left(5 \times 10^{4}\right.$ cells in $0.35-\mathrm{ml}$ serum-free DMEM per well) were seeded into the top chamber of a 10-well invasion chamber assay plate. DMEM supplemented with $10 \%$ FBS was placed in the lower chamber, and a matrigel-coated membrane was inserted between the two chambers. After incubation for $24 \mathrm{~h}$ at $37^{\circ} \mathrm{C}$, the membranes were fixed and stained with a Hemacolor rapid staining kit (Merck $\mathrm{KGaA}$ ). Cells from five random microscopic fields (each $0.5 \mathrm{~mm}^{2}$ ) were counted using a hematocytometer under a light microscope (Zeiss).

Immunofluorescence. To confirm morphological changes, cells were washed thrice with PBS, fixed in $4 \%$ paraformaldehyde (PFA) for $10 \mathrm{~min}$ at room temperature, and permeabilized with PBS containing $0.25 \%$ Triton X-100 (PBST) for 10-15 min at room temperature. After three washes with PBS, cells were blocked with $1 \%$ bovine serum albumin for $30 \mathrm{~min}$. Samples were incubated overnight at $4^{\circ} \mathrm{C}$ with the relevant antibodies anti-MIF (1:500; Cell Signaling Technology) and anti-F actin (1:500; Santa-Cruz Biotechnology Inc.) for $2 \mathrm{~h}$ at room temperature. After three washes with PBS, immune-labeled cells were counterstained with $50 \mu 1$ of DAPI at $37^{\circ} \mathrm{C}$ for $10 \mathrm{~min}$. Cells were analyzed using a laser scanning confocal microscope (Leica Microsystems).

Immunoprecipitation. Immunoprecipitation analysis was carried out as previously described (16). Briefly, cells were lysed using a protein lysis buffer $[1 \%(\mathrm{v} / \mathrm{v})$ Triton X-100, $150 \mathrm{mM} \mathrm{NaCl}, 50 \mathrm{mM}$ Tris-HCl, $\mathrm{pH}$ 8.0, 5 mM ethylenediaminetetraacetic acid (EDTA), and protease inhibitors], and cell lysates were incubated overnight with primary anti- $\beta$-catenin and protein $\mathrm{A}$ or $\mathrm{G}$ beads (GE Healthcare, Uppsala, Sweden) at $4^{\circ} \mathrm{C}$ on a rotator. The beads were washed, boiled in Laemmli buffer, and processed for western blotting.

Animals. Five-week-old male athymic nude mice (BL-6/Nu, 20-25 g; Orient Bio Co., Ltd., Seoul, Korea) were housed under controlled light conditions and provided water ad libitum. All experimental procedures involving animals were performed in compliance with institutional and governmental requirements and approved by the Institutional Animal Care and Use Committee (approval no. CIACUC2015-A0032), Chosun University, Gwangju, Korea.

Intracardiac xenograft model. Twenty mice were subjected to intracardiac injections of $\mathrm{LNCaP}^{\mathrm{Vec}}$ or $\mathrm{LNCaP}^{\mathrm{CD} 133+}$ cells and 10 mice subjected PBS as mock mice to examine the ability of PC cells to metastasize to bone, respectively. Before injection, the cells were transfected with the pGL4.5 vector plasmid encoding luciferase (Promega Corporation, Madison, WI, USA). The stably transfected cells were grown in Hank's balanced salt solution (HBSS; Welgene) supplemented with hygromycin ( $2 \mathrm{mg} / \mathrm{ml}$; Sigma-Aldrich; Merck KGaA) and, luciferase activity was measured using the Luciferase Assay System (Promega Corporation) and detected by luminometer
GENios Plus (Tecan Group Ltd., Salzburg, Austria). The severe combined immunodeficient mice were anesthetized using isoflurane gas. Subsequently, $\mathrm{LNCaP}^{\mathrm{Vec}+}$ or $\mathrm{LNCaP}^{\mathrm{CD} 133+}$ cells $\left(1 \times 10^{5}\right.$ cells per mouse) were injected into the left cardiac ventricle, as per the technique first described by Arguello et al (17) with some modifications. After 4 weeks, images of tumor-bearing tissues excised from mice during necropsy were obtained.

Bioluminescence imaging. After intracardiac injection, mice were weekly imaged via bioluminescence for 4-6 weeks using the IVIS ${ }^{\circledR}$ imaging system (PerkinElmer, Waltham, MA, USA) at the Korea Basic Science Institute (Gwangju, Korea). Images were captured and processed using the Living Image ${ }^{\circledR}$ v.4.2 software. Anesthesia was induced using inhaled isoflurane and maintained with $2 \%$ isoflurane mixed with oxygen/nitrogen via nose cone delivery. d-Luciferin (3 mg dissolved in water) was administered at $150 \mathrm{mg} / \mathrm{kg}$ in Dulbecco's phosphate-buffered saline (DPBS) via intraperitoneal injection. Optical imaging was acquired approximately 10-15 min later.

Histological analysis of mouse tissues. Tumor-bearing tissues were fixed in cold 4\% PFA. Bone tissue was first decalcified using a sodium citrate solution before processing onto histological slides. Decalcified bones were cut at the midpoint and embedded in paraffin blocks. Fluorescence from serial paraffin sections was monitored via fluorescence microscopy (Leica Microsystems). Tissues were stained with hematoxylin and eosin (H\&E) stain, and images were acquired using a microscope slide scanner (3D-HISTECH Ltd., Budapest, Hungary).

Cytokine profiling. Supernatants from $\mathrm{LNCaP}^{\mathrm{Vec}}$ and $\mathrm{LNCaP}^{\mathrm{CD} 133+}$ cells and sera from tumor-bearing mice were collected and assayed using a cytokine array kit (R\&D Systems, Minneapolis, MN, USA), according to the manufacturer's instructions. The cytokines examined using this technique are listed in Table I. Cytokines were detected using the ECL detection kit (Amersham) and quantified via densitometric analysis using ImageJ software (Scion Corp, MD, USA).

Reverse transcription-quantitative PCR (qPCR) analysis. Total RNA was extracted from cells using TRIzol ${ }^{\circledR}$ reagent (Invitrogen; Thermo Fisher Scientific, Inc.). cDNA was synthesized from $2 \mu \mathrm{g}$ total RNA using the Super-Script II First-Strand Synthesis System (Invitrogen; Thermo Fisher Scientific, Inc.). mRNA levels were measured via $\mathrm{qPCR}$, and the Gapdh gene was used as an endogenous control. Sequences of the primers used to target various genes are listed in Table II.

Immunohistochemical analysis of bone specimens. Paraffin sections were deparaffinized in three solutions of xylene and rehydrated in a graded series of ethanol solutions. For antigen retrieval, slides were placed in $0.01 \mathrm{M}$ citrate buffer at pH 6.0 and heated in a steamer for $30 \mathrm{~min}$. Endogenous peroxidases were quenched by incubating the samples with $3 \%$ hydrogen peroxide for $20 \mathrm{~min}$ at room temperature. Sections were incubated overnight at $4^{\circ} \mathrm{C}$ using a 1:50 dilution of the primary antibody against MIF (Santa-Cruz Biotechnology Inc.). Sections were then incubated for $30 \mathrm{~min}$ with a biotinylated secondary antibody (LSAB system HRP 
Table I. List of human inflammatory cytokines examined using the antibody array (R\&D Systems).

\begin{tabular}{|c|c|c|c|}
\hline Coordinate & Analyte/control & Entrez gene ID & Alternate nomenclature \\
\hline $\mathrm{A} 1, \mathrm{~A} 2$ & Reference spots & $\mathrm{N} / \mathrm{A}$ & RS \\
\hline $\mathrm{A} 3, \mathrm{~A} 4$ & Adiponectin & 9370 & Acrp30 \\
\hline A5, A6 & Apolipoprotein A-I & 335 & ApoA1 \\
\hline $\mathrm{A} 7, \mathrm{~A} 8$ & Angiogenin & 283 & - \\
\hline A9, A10 & Angiopoietin-1 & 284 & Ang-1, ANGPT1 \\
\hline $\mathrm{A} 11, \mathrm{~A} 12$ & Angiopoietin-2 & 285 & Ang-2, ANGPT2 \\
\hline $\mathrm{A} 13, \mathrm{~A} 14$ & BAFF & 10673 & BLyS, TNFSF13B \\
\hline A15, A16 & BDNF & 627 & Brain-derived neurotrophic factor \\
\hline $\mathrm{A} 17, \mathrm{~A} 18$ & Complement component C5/C5a & 727 & C5/C5a \\
\hline A19, A20 & CD14 & 929 & - \\
\hline $\mathrm{A} 21, \mathrm{~A} 22$ & CD30 & 943 & TNFRSF8 \\
\hline $\mathrm{A} 23, \mathrm{~A} 24$ & Reference spots & $\mathrm{N} / \mathrm{A}$ & $\mathrm{RS}$ \\
\hline B3, B4 & CD40 ligand & 959 & CD40L, TNFSF5, CD154, TRAP \\
\hline B5, B6 & Chitinase 3-like 1 & 1116 & CHI3L1, YKL-40 \\
\hline B7, B8 & Complement factor D & 1675 & Adipsin, CFD \\
\hline B9, B10 & C-Reactive protein & 1401 & CRP \\
\hline B11, B12 & Cripto-1 & 6997 & $\begin{array}{l}\text { Teratocarcinoma-derived growth } \\
\text { factor }\end{array}$ \\
\hline B13, B14 & Cystatin C & 1471 & CST3, ARMD11 \\
\hline B15, B16 & Dkk-1 & 22943 & Dickkopf-1 \\
\hline B17, B18 & DPPIV & 1803 & CD26, DPP4, dipeptidyl-peptidase IV \\
\hline B19, B20 & EGF & 1950 & Epidermal growth factor \\
\hline B21, B22 & Emmprin & 682 & CD147, basigin \\
\hline $\mathrm{C} 3, \mathrm{C} 4$ & ENA-78 & 6374 & CXCL5 \\
\hline $\mathrm{C} 5, \mathrm{C} 6$ & Endoglin & 2022 & CD105, ENG \\
\hline $\mathrm{C} 7, \mathrm{C} 8$ & Fas ligand & 356 & TNFSF6, CD178, CD95L \\
\hline $\mathrm{C} 9, \mathrm{C} 10$ & FGF basic & 2247 & FGF-2 \\
\hline $\mathrm{C} 11, \mathrm{C} 12$ & FGF-7 & 2252 & KGF \\
\hline $\mathrm{C} 13, \mathrm{C} 14$ & FGF-19 & 9965 & - \\
\hline $\mathrm{C} 15, \mathrm{C} 16$ & Flt-3 ligand & 2323 & FLT3LG \\
\hline $\mathrm{C} 17, \mathrm{C} 18$ & G-CSF & 1440 & CSF3 \\
\hline $\mathrm{C} 19, \mathrm{C} 20$ & GDF-15 & 9518 & MIC-1 \\
\hline $\mathrm{C} 21, \mathrm{C} 22$ & GM-CSF & 1437 & CSF2 \\
\hline D1, D2 & $\mathrm{GRO} \alpha$ & 2919 & CXCL1, MSGA- $\alpha$ \\
\hline D3, D4 & Growth hormone & 2688 & GH, somatotropin \\
\hline D5, D6 & HGF & 3082 & Scatter factor, SF \\
\hline D7, D8 & ICAM-1 & 3383 & CD54 \\
\hline D9, D10 & IFN- $\gamma$ & 3458 & IFNG \\
\hline D11, D12 & IGFBP-2 & 3485 & - \\
\hline
\end{tabular}

kit; DakoCytomation, Glostrup, Denmark), rinsed in PBS, and incubated for $30 \mathrm{~min}$ with a streptavidin-peroxidase conjugate (LSAB; DakoCytomation). The reaction was developed for 5 min using 3, 30-diaminobenzidine tetrahydrochloride (Sigma-Aldrich; Merck KGaA). Slides were counterstained in hematoxylin, dehydrated, and covered with a cover slip. Negative and positive controls were simultaneously analyzed. Positive controls comprised mammary tissues. The slides were captured using a microscope slide scanner (3D-HISTECH Ltd., Budapest, Hungary).
Statistical analysis. One-way analysis of variance (ANOVA) followed by Sidak's multiple comparison test (unless specifically mentioned otherwise) were used for statistical analyses. $\mathrm{P}<0.05$ was considered to indicate a statistically significant difference. Data are expressed as the mean \pm standard deviation (SD) unless specified otherwise. Data were analyzed using the SPSS v.20.0 software program for Windows (SPSS, Inc., Chicago, IL, USA). GraphPad Prism v.6.00 software program for Windows (GraphPad, La Jolla, CA, USA) was used to analyze data from in vitro and in vivo experiments. 
A
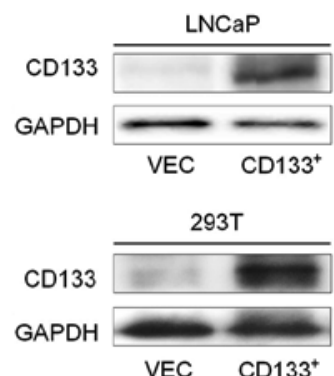
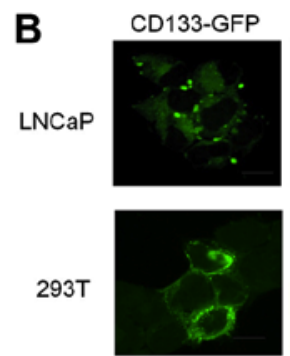
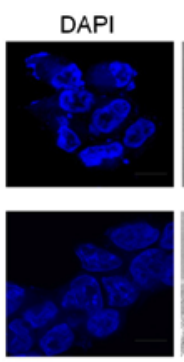
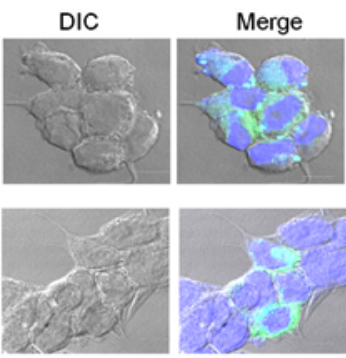

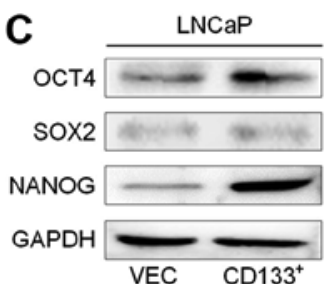

D
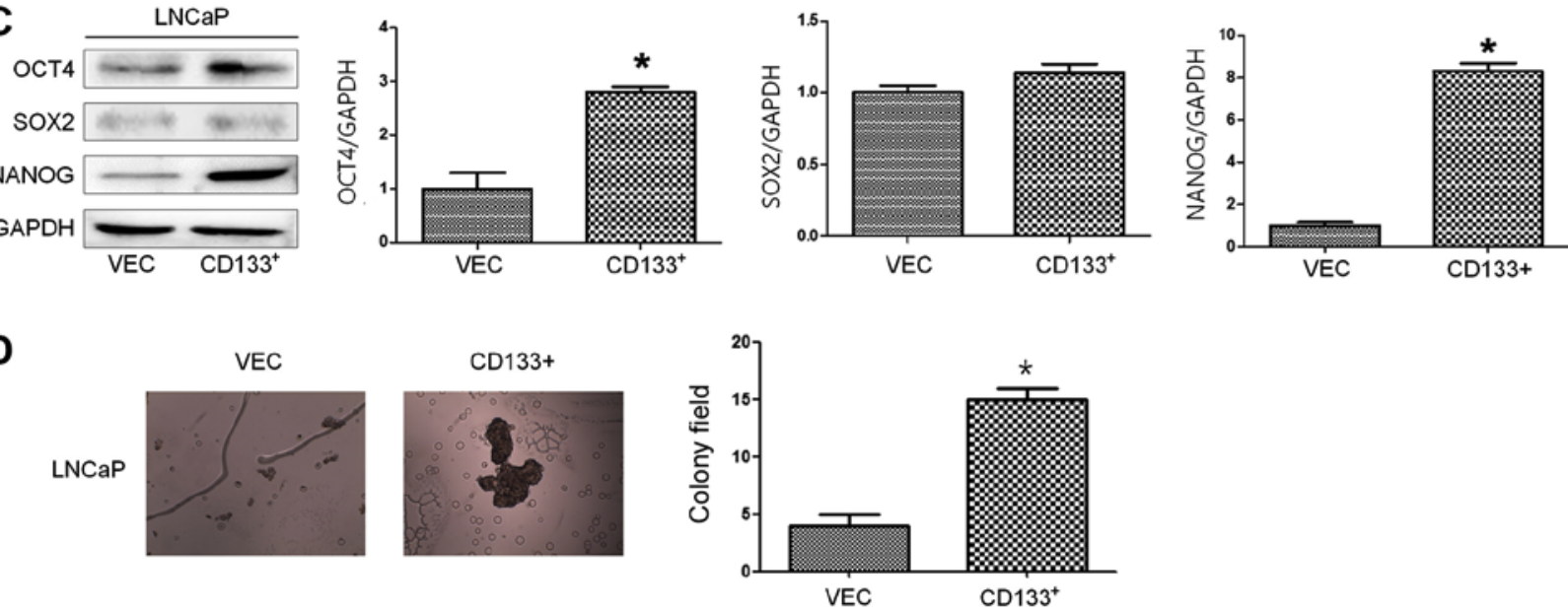

Figure 1. Overexpression of CD133 in PC cell lines. (A) Western blot analysis of CD133 expression in LNCaPvec (Vec) and LNCaPCD133+ (CD133) cells $293 \mathrm{~T}$ cells were transiently transfected with pcDNA3.1/N-terminal green fluorescent protein (NT-GFP) or pcDNA3.1/NTGFPCD133, and 293T ${ }^{\mathrm{Vec}}$ $(\mathrm{Vec}) / 293 \mathrm{~T}^{\mathrm{CD133+}}$ (CD133) cells were used as a positive control. (B) Confocal microscopy analysis of GFP-CD133 expression by stably or transiently transfected LNCaP/293T-GFP-CD133 cells. Nuclei were stained with DAPI, blue. Magnification, x630; scale bar, $10 \mu \mathrm{m}$. (C) Western blot analysis of stemness-related protein expression. GAPDH was used as a loading control. Similar results were obtained in three separate experiments. (D) Stable overexpression of CD133 led to a significant increase in colony-forming ability. Magnification, $\mathrm{x} 100$; scale bar, $100 \mu \mathrm{m}$. Bar graphs represent the mean \pm standard deviation. ${ }^{*} \mathrm{P}<0.05 \mathrm{vs}$. VEC. PC; prostate cancer; NT-GFP, N-terminal green fluorescent protein.

\section{Results}

Stable overexpression of CD133 in LNCAP cells. To evaluate the effect of CD133 overexpression in vitro, we established a stable cell line overexpressing CD133 under the control of a constitutive promoter. We transfected LNCaP cells with either CD133 or an empty vector tagged with GFP. A representative $\mathrm{CD} 133$ clone was selected from $\mathrm{LNCaP}^{\mathrm{CD} 133+}$ cells and compared against control cells transfected with the empty vector $\left(\mathrm{LNCaP}^{\mathrm{Vec}}\right)$. Transiently transfected $293 \mathrm{~T}^{\mathrm{Vec}}$ or $293 \mathrm{~T}^{\mathrm{CD} 133+}$ cells were used as a positive control. Basal expression of $\mathrm{CD} 133$ protein in $\mathrm{LNCaP}^{\mathrm{Vec}}$ cells was very low; however, the basal expression of CD133 was high in stable CD133-transfected cells ( $\mathrm{LNCaP}^{\mathrm{CD} 133+}$ ) and transiently transfected 293T cells (Fig. 1A). Green fluorescence was observed in the cytosol and membrane of $\mathrm{LNCaP}^{\mathrm{CD} 133+}$ cells (Fig. 1B).

To explore the function of CD133 in cancer stemness, we evaluated the acquisition of CSC properties such as increased ability to form tumor spheres and expression of stem cell markers such as Oct-4, SOX2, and NANOG. The expression levels of Oct-4 and NANOG were significantly elevated in $\mathrm{LNCaP}^{\mathrm{CD} 133+}$ cells, consistent with the increase in stemness properties (Fig. 1C). Stemness was also confirmed by a colony-formation assay. Colony-forming ability was significantly elevated in $\mathrm{LNCaP}^{\mathrm{CD} 133+}$ cells, in line with the elevated expression of stemness factors (Fig. 1D). These results suggest
Table II. Gene primer sequences.

\begin{tabular}{lll}
\hline $\begin{array}{l}\text { Gene } \\
\text { name }\end{array}$ & \multicolumn{1}{c}{$\begin{array}{c}\text { Upstream } \\
\text { primer }\left(5^{\prime}-3^{\prime}\right)\end{array}$} & \multicolumn{1}{c}{$\begin{array}{l}\text { Downstream } \\
\text { primer }\left(3^{\prime}-5^{\prime}\right)\end{array}$} \\
\hline$M I F$ & GCAGAACCGCT & GGCTCTTAGGC \\
& CCTACAGCA & GAAGGTGGA \\
GAPDH & TGGAATCCACT & GGTTCACGCCC \\
& GGCGTCTTC & ATCACAAAC \\
\hline
\end{tabular}

Table III. Characteristics of the tumor formations.

\begin{tabular}{llll}
\hline Cell Line & Injection & Cell no. & Tumor formation \\
\hline LNCaP $^{\mathrm{Vec}}$ & Intracardiac & $1 \times 10^{5}$ & $2 / 10(20 \%)$ \\
$\mathrm{LNCaP}^{\mathrm{CD} 133+}$ & Intracardiac & $1 \times 10^{5}$ & $8 / 10(80 \%)$ \\
\hline
\end{tabular}

that the increase in colony-forming ability and Oct-4 and NANOG expression conferred stem cell-like properties during ectopic overexpression of CD133.

EMT-related properties in CD133-overexpressing LNCaP cells. CD133 overexpression in LNCaP cells, as determined by 
A
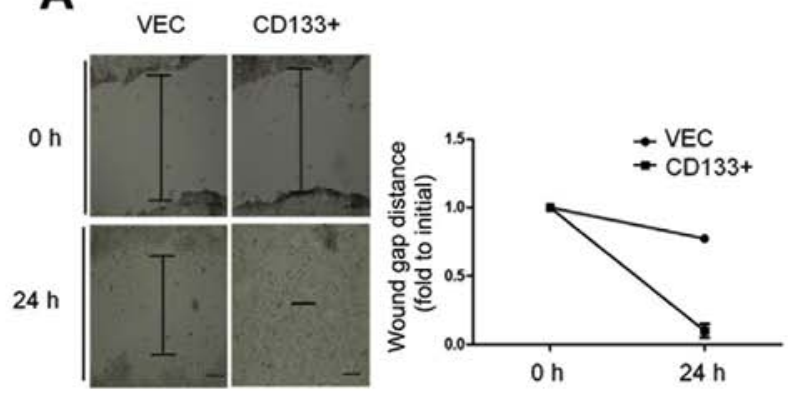

B

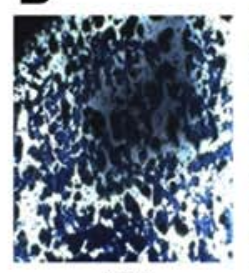

VEC
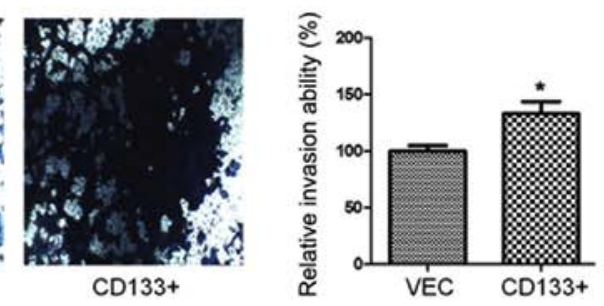

C

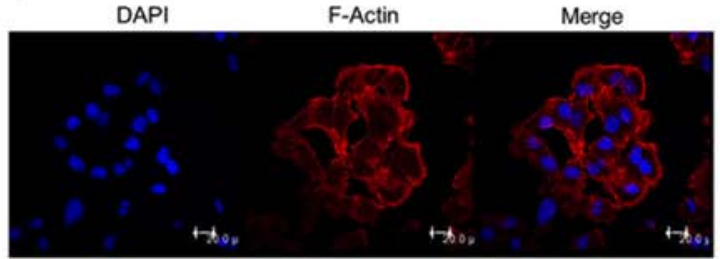

CD133+

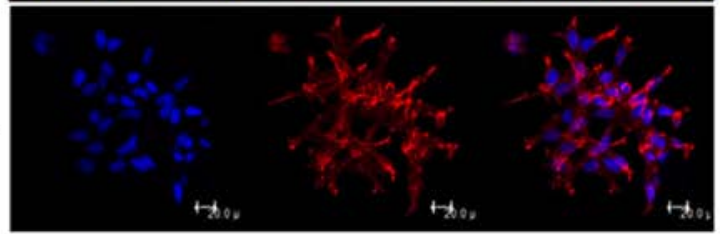

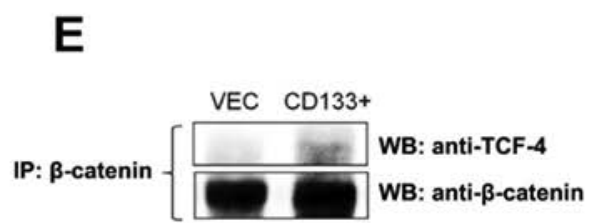

D
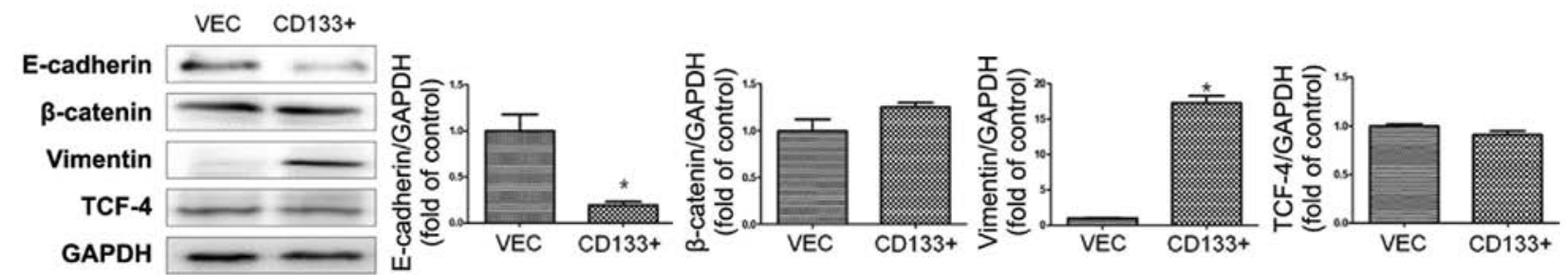

Figure 2. CD133 overexpression promotes EMT in LNCaP cells. (A) CD133 overexpression led to a significant increase in the migratory capacity of LNCaP cells, as evident by a decrease in the wound gap distance at $24 \mathrm{~h}$. Magnification, x100; Scale bar, $100 \mu \mathrm{m}$. The data in the associated graphs are expressed as the mean \pm SD. (B) CD133 overexpression significantly increased the invasiveness of LNCaP cells. Magnification, $x 100 ;$ scale bar, $100 \mu \mathrm{m}$. Data in the associated bar graphs are expressed as the mean \pm SD. (C) Confocal microscopy images of F-actin expression in LNCaP cells. Nuclei were stained with DAPI. Magnification, x630; scale bar, $20 \mu \mathrm{m}$. (D) Expression of EMT-related proteins was characterized by western blotting. GAPDH was used as a loading control. Results are representative of three separate experiments. (E) Immunoprecipitation of $\beta$-catenin. Each blot was obtained under the same experimental conditions. " $\mathrm{P}<0.05$ vs. VEC. EMT, epithelial-mesenchymal transition.

wound healing and cell invasion assays, induced a significant increase in cell migration and invasion. After $24 \mathrm{~h}$, the artificial wound gaps became significantly narrower in $\mathrm{LNCaP}^{\mathrm{CD} 133+}$ cells than in $\mathrm{LNCaP}^{\mathrm{Vec}}$ cells (Fig. 2A). Furthermore, the invasive abilities of $\mathrm{LNCaP}^{\mathrm{CD} 133+}$ cells significantly increased (Fig. 2B). To monitor morphological changes in $\mathrm{LNCaP}$ cells, immunofluorescence analysis for F-actin was performed using confocal microscopy. The number of spindle and discontiguous cells observed in the $\mathrm{LNCaP}^{\mathrm{CD} 133+}$ group was higher than that observed in the $\mathrm{LNCaP}^{\mathrm{Vec}}$ group (Fig. 2C).

To identify factors associated with altered invasiveness and migration caused by ectopic overexpression of CD133, we monitored levels of epithelial and mesenchymal markers in PC cells. Protein expression analyses revealed a slightly lower expression of epithelial marker E-cadherin in $\mathrm{LNCaP}^{\mathrm{CD} 133+}$ cells than in $\mathrm{LNCaP}^{\mathrm{Vec}}$ cells (Fig. 2D). In contrast, expression of the mesenchymal marker vimentin was significantly upregulated in $\mathrm{LNCaP}^{\mathrm{CD} 133+}$ cells. Further, analysis of $\beta$-catenin-associated signal transduction was carried out via immunoprecipitation in $\mathrm{LnCaP}^{\mathrm{CD} 133+}$ cells (Fig. 2E). CD133 overexpression led to a significant increase in binding between $\beta$-catenin and TCF-4, an EMT-inducing transcriptional factor in cancer cells in compared with $\mathrm{LnCaP}^{\mathrm{vec}}$ cells as a negative control. These data strongly support the idea that CD133 is essential for increased and decreased expression of vimentin and E-cadherin, respectively, leading to subsequent EMT and metastasis in PC cells.

CD133 promotes LNCaP-induced bone metastasis in vivo. Both of $\mathrm{LNCaP}^{\mathrm{Vec}}$ and $\mathrm{LNCaP}^{\mathrm{CD} 133+}$ cells were labeled with luciferase, and the cells showed a similar luciferase activities (Fig. 3A). An then we injected $\mathrm{LNCaP}^{\mathrm{Vec}}$ and $\mathrm{LNCaP}^{\mathrm{CD} 133+}$ cells into the left cardiac ventricle of male nude mice at $0.5 \times 10^{6}$ cells/mouse. The mice were imaged weekly, starting from week 4 after intracardiac injection. The results of PBS (mock) injection and injection of $\mathrm{LNCaP}^{\mathrm{Vec}}$ and $\mathrm{LNCaP}^{\mathrm{CD} 133+}$ cells are shown in the whole-mouse image in Fig. 3B. A large hot-spot and a small spot of bioluminescence were observed in the whole body following $\mathrm{LNCaP}^{\mathrm{CD} 133+}$ cell injection. Only $20 \%$ 
A

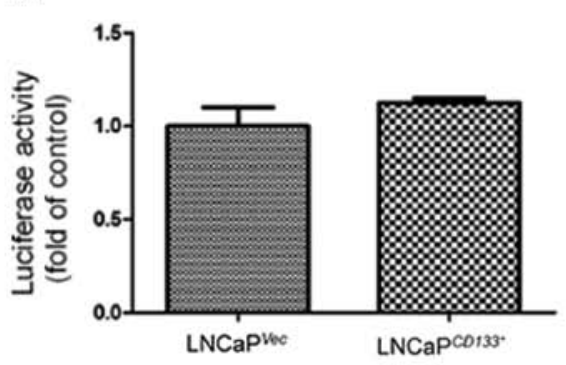

B

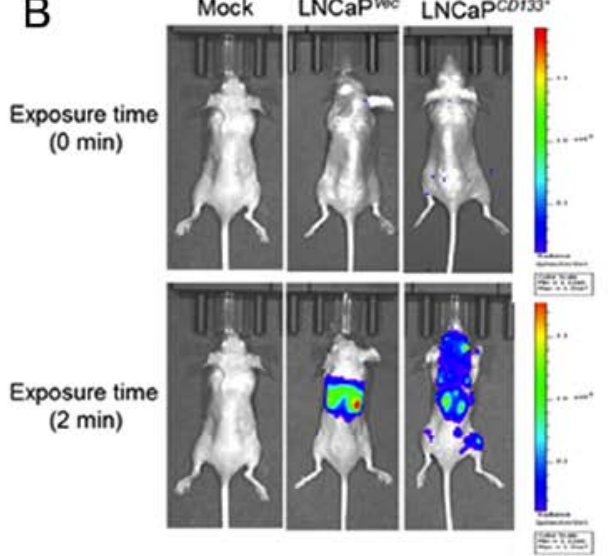

C
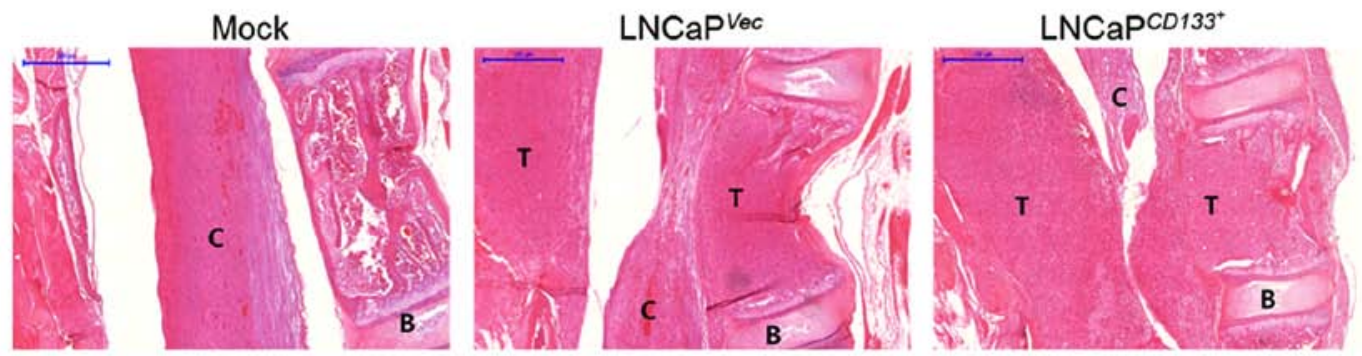

D
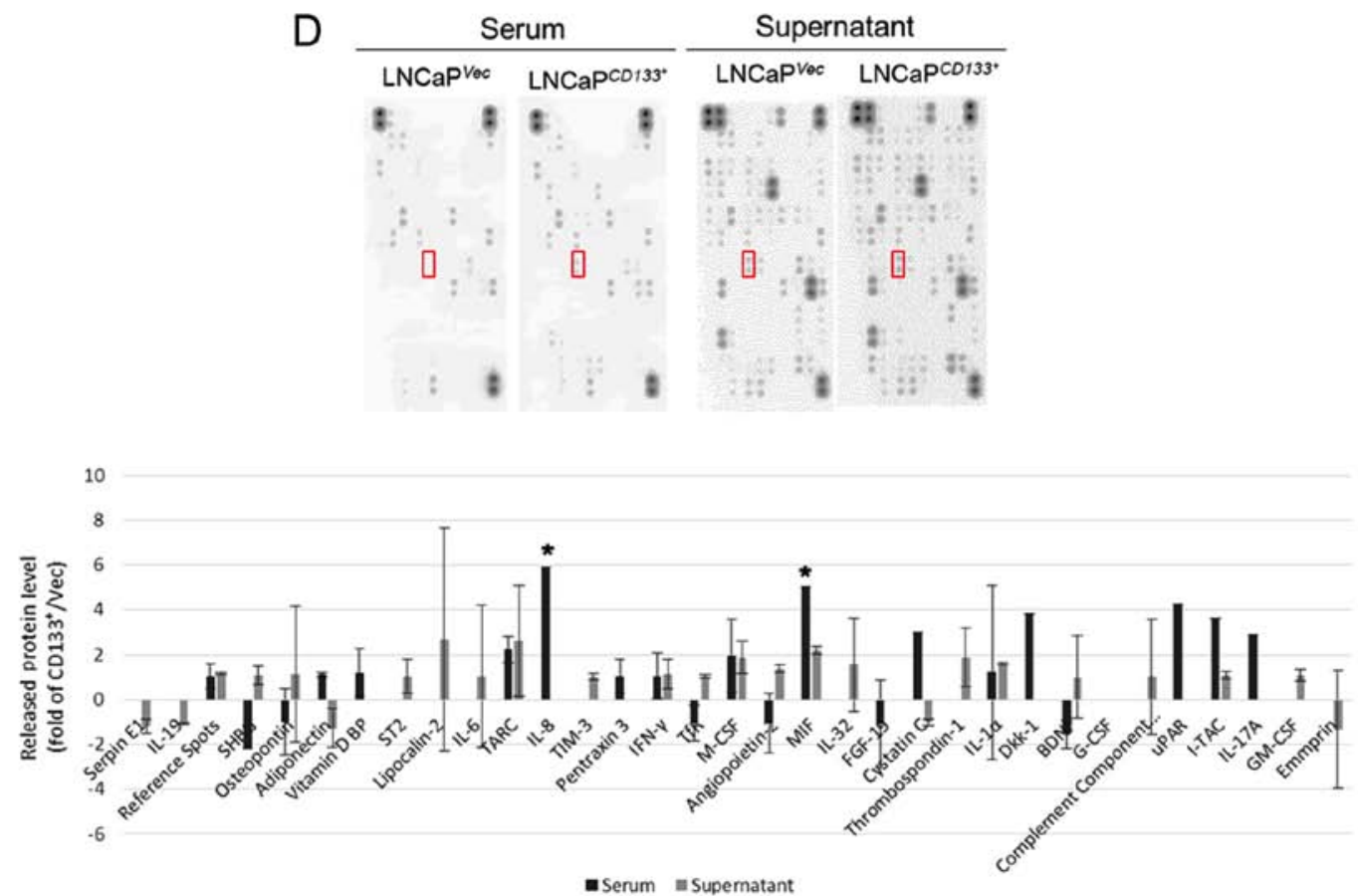

Figure 3. Comparison of mouse tumors. (A) Luciferase activities between $\mathrm{LNCaP}^{\mathrm{Vec}}(\mathrm{Vec})$ and $\mathrm{LNCaP}^{\mathrm{CD} 133+}\left(\mathrm{CD} 133^{+}\right)$cells. (B) Tumor growth and multiple metastases were monitored over time via in vivo bioluminescence imaging. Data per representative mouse are shown. A large hot-spot of bioluminescence was observed in vivo following inoculation of mice with $\mathrm{LNCaP}^{\mathrm{Vec}}(\mathrm{Vec})$ cells. Multiple localized and distant metastases were induced in vivo after injection of $\mathrm{LNCaP}^{\mathrm{CD} 133+}\left(\mathrm{CD}_{133^{+}}\right)$cells into the hearts of nude mice. Colored bars indicate the bioluminescence signal intensity range $\left(\right.$photon $\left.^{-1} \mathrm{~s}^{-1} \mathrm{~cm}^{-2} \mathrm{steradian}^{-1}\right)$. (C) Hematoxylin and eosin staining of mouse tissue sections at the end of the study period. Metastases in representative histological sections of spine tissues are shown (magnification, x20; scale bar, $200 \mu \mathrm{m})$. (D) Cytokine profiling of $\mathrm{LNCaP}^{\mathrm{Vec}}(\mathrm{Vec}) / \mathrm{LNCaP}^{\mathrm{CD} 133+}(\mathrm{CD} 133+)$ cells. Culture supernatant from each cell line and serum from each mouse were harvested after $24 \mathrm{~h}$ and assayed using a cytokine profile array kit. Bar represents the mean ratio \pm SD from two experiments. " $\mathrm{P}<0.05$ vs. respective supernatant. $\mathrm{B}$, bone; $\mathrm{T}$, tumor mass; $\mathrm{C}$, spinal cord; IL-8, interleukin-8; MIF, macrophage migration inhibitory factor.

of animals inoculated with $\mathrm{LNCaP}^{\mathrm{Vec}}$ cells developed skeletal tumors $(n=10)$ as compared with $80 \%$ of those inoculated with $\mathrm{LNCaP}^{\mathrm{CD} 133+}$ cells (Table III).
We performed H\&E staining to examine the histological features of skeletal tumors formed by $\mathrm{LNCaP}^{\mathrm{Vec}} / \mathrm{LNCaP}^{\mathrm{CD} 133+}$ cells inoculated into mice via intracardiac injection. As 

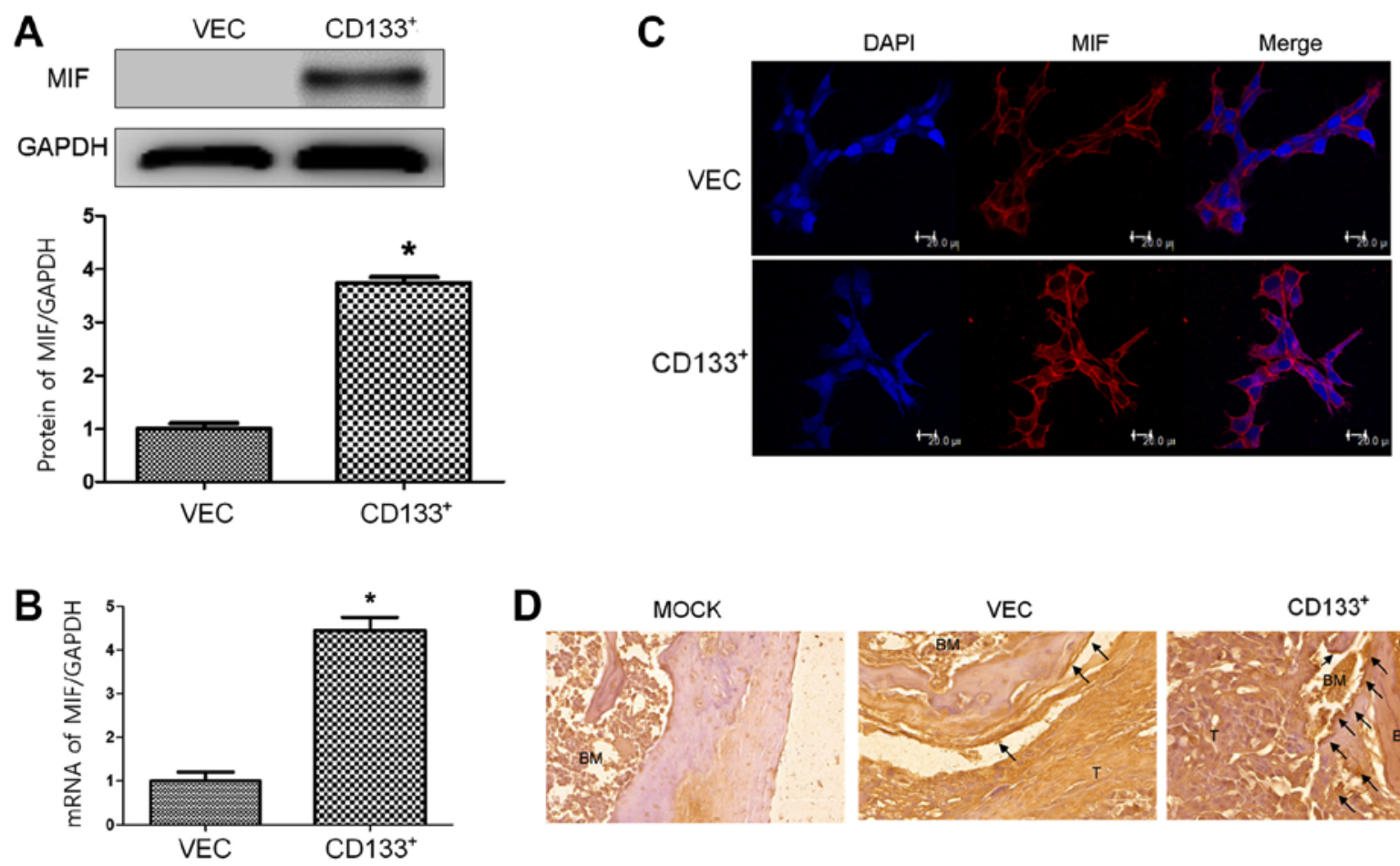

D

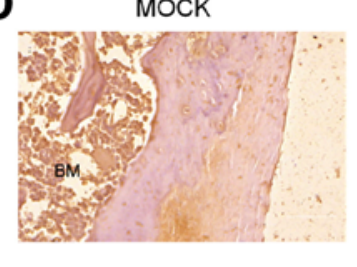

VEC

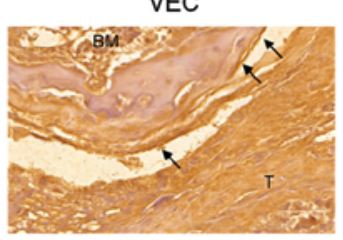

$\mathrm{CD}_{133^{+}}$

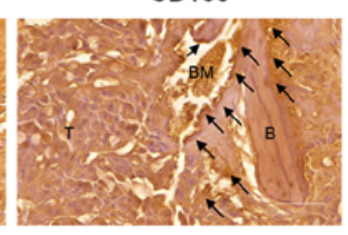

Figure 4. In vitro and in vivo expression of $\mathrm{MIF}$ in $\mathrm{LNCaP}^{\mathrm{Vec}}$ and $\mathrm{LNCaP}^{\mathrm{CD} 133+}$ cells. (A) Expression of $\mathrm{OPN}$ in $\mathrm{LNCaP}^{\mathrm{Vec}}(\mathrm{Vec})$ and $\mathrm{LNCaP}^{\mathrm{CD} 133+}(\mathrm{CD} 133+)$ cells was measured by western blotting. GAPDH was used as a loading control. (B) MIF mRNA expression was characterized in $\mathrm{LNCaP}^{\mathrm{Vec}}(\mathrm{Vec})$ and $\mathrm{LNCaP}$ (D133+ (CD133+) cells via reverse transcription-quantitative PCR. (C) Confocal microscopy of MIF expression in LNCaP cells. Nuclei were stained with DAPI (blue). Magnification, x630; scale bar, $20 \mu \mathrm{m}$. (D) Immunohistochemical analysis of MIF in mouse tissue sections at the end of the study period. Metastases in representative histological sections of spine tissues are shown (magnification, $\mathrm{x} 200$; scale bar, $20 \mu \mathrm{m}$ ) and black arrows indicate strong MIF positive cells near bone tissue. " $\mathrm{P}<0.05$ vs. VEC. MIF, macrophage migration inhibitory factor, B, bone; $\mathrm{T}$, tumor mass; $\mathrm{C}$, spinal cord; OPN, osteopontin; MIF, macrophage migration inhibitory factor.

shown in Fig. 3C, gross examination of excised spines in mice injected with $\mathrm{LNCaP}^{\mathrm{Vec}}$ or $\mathrm{LNCaP}^{\mathrm{CD} 133+}$ cells showed that the tumor mass occupied the primary spongiosum (trabecular epiphysis) and displaced the bone marrow cells. In particular, an apparent margin between the spinal cord and metastatic tumors was observed in $\mathrm{LNCaP}^{\mathrm{Vec}}$-inoculated mice. However, metastatic tumors invading the spinal cord and discursive osteolytic features of vertebrae were observed in $\mathrm{LNCaP}^{\mathrm{CD} 133+}$ cell-inoculated mice. We aimed to identify the secreted molecules that played a critical role in $\mathrm{LNCaP}^{\mathrm{CD} 133+}$ cell-induced bone metastasis through a cytokine screening using a proteome array cytokine kit (Fig. 3D). CD133 overexpression in LNCaP cells led to a marked increase in the release of interleukin 8 and MIF from mouse serum. MIF expression increased in the supernatants of $\mathrm{LNCaP}^{\mathrm{CD} 133+}$ cells. These data suggest that ectopic overexpression of CD133 might lead to a significantly increased risk of bone metastatic cancer. Further, increased MIF expression may contribute to PC metastasis in the bone.

Expression of MIF in primary PC and metastatic lesions. To investigate the role of MIF in bone metastasis of LNCaP cells, its mRNA and protein expression levels were analyzed. MIF protein (Fig. 4A) and mRNA (Fig. 4B) levels were higher in $\mathrm{LNCaP}^{\mathrm{CD} 133+}$ cells than in $\mathrm{LNCaP}^{\mathrm{Vec}}$ cells. To monitor the cellular distribution of MIF in LNCaP cells, MIF immunofluorescence was performed. MIF expression in the membrane and cytosol was higher in $\mathrm{LNCaP}^{\mathrm{CD} 133+}$ cells than in $\mathrm{LNCaP}^{\mathrm{Vec}}$ cells (Fig. 4C).
In the immunohistochemical study, MIF expression increased around the tumor mass and trabecular epiphysis region of bones inoculated with $\mathrm{LNCaP}^{\mathrm{CD} 133+}$ cells. These observations suggest that ectopic overexpression of CD133 leads to increased MIF expression in CD133+ cells and activation of bones adjacent to the tumor, particularly in $\mathrm{LNCaP}$ cell-injected bones, and that CD133 expression is associated with PC metastasis to the bone.

\section{Discussion}

Bone is a common site of distant metastasis in PC. Association of bone and metastatic cancer cells is important in site-specific manifestation of PC (18). There are no curative treatments for the disease at this stage, and bone metastasis remains a devastating complication of advanced PC, despite advances in understanding of mechanisms underlying the basic molecular biology of this process. The existence and identification of CSCs reveal the pivotal roles that these cells play in metastasis (19). In the present study, we identified CSC-like cells following ectopic overexpression of CD133 in the PC cell line LNCaP. This phenomenon gave rise to genetic variation in PC cells and altered expression of several factors related to stemness, including NANOG and Oct-4, resulting in increased colony-forming abilities. Furthermore, genetic modulation of CD133 altered expression of EMT-related factors increased vimentin expression and decreased E-cadherin expression, resulting in the generation of a complex with TCF- 4 and $\beta$-catenin. Although 
the role of EMT in PC remains unclear, several factors involved in EMT or related pathways have been identified as key molecules in cancer cell invasion and metastasis. There is the strong correlation between CD133 and EMT factors that may explain the invasiveness and migration of $\mathrm{LNCaP}^{\mathrm{CD} 133+}$ cells.

Recent studies have shown that EMT may induce differentiation of cancer cells into a CSC-like state. EMT plays a critical role in the process of development and wound healing; however, recent studies have linked EMT with human pathology, including cancer metastasis (20). However, no research has yet revealed the mechanisms underlying this phenomenon or identified the source of cells with both EMT and stem cell properties. In the present study, we show for the first time that PC cells via ectopic overexpression of CD133 may present mesenchymal characteristics and stem cell properties. In addition, LNCaP cells were originated from not bone metastatic PC but lymph node, it confirmed that ectopic overexpression of CD133 in $\mathrm{LNCaP}$ led to promote the ability of bone metastasis in the present study. These results imply that CSCs may induce local and distant metastases to the bone by acquiring mesenchymal features, which may greatly facilitate systemic dissemination from the primary mass. Furthermore, the redundant regulation of $\beta$-catenin/TCF-4 signaling during tumor metastasis through several EMT-inducing signals suggests that this expression is critical in the initiation and maintenance of EMT. According to recent studies, the microenvironment at the invasive front of cancer cells, especially secretion of factors such as hepatocyte growth factor by stromal myofibroblasts near dedifferentiated cancer cells, plays a key role in the nuclear translocation of $\beta$-catenin and activation of $\beta$-catenin/TCF-4 signaling (16).

We explored factors that play a critical role in CD133+ $\mathrm{PC}$ cell-induced bone metastasis. $\mathrm{LNCaP}^{\mathrm{Vec}}$ and $\mathrm{LNCaP}^{\mathrm{CD} 133+}$ cells were inoculated into athymic nude mice via intracardiac injection, and showed an osteolytic bone metastasis with a similar result of previous study (21). And then, secreted cytokines with paracrine and endocrine actions were evaluated using mouse serum in array kits. Histological analysis revealed that CD133+ cells generated larger and more aggressive tumors than their wild-type counterparts, while $\mathrm{LNCaP}^{\mathrm{CD} 133+}$ cells showed higher expression of MIF than $\mathrm{LNCaP}^{\mathrm{Vec}}$ cells. Moreover, MIF is a pleiotropic inflammatory cytokine with chemokine-like functions and may bind and signal via several receptors, including $\mathrm{CD} 74, \mathrm{C}-\mathrm{X}-\mathrm{C}$ motif chemokine receptor 2 (CXCR2), and CXCR4. MIF may play a central role in bone metastasis of $\mathrm{PC}$ and perform critical biological functions (22). MIF is known to induce osteoclast differentiation and contribute to the progression of various bone and periodontal diseases (23). A previous study has shown that binding of both MIF and stromal cell-derived factor 1 chemokines to CXCR4 may trigger chemotaxis of osteoclast precursors and enhance osteoclastogenesis (24). The interaction of MIF with chemokine receptors may explain its ability to induce macrophage migration and osteoclastogenesis. Our current findings support the conclusion that while a physiological target is yet unidentified, tautomerase activity is important for MIF functionality and may contribute to tumor growth and metastasis. Tropism of $\mathrm{LNCaP}^{\mathrm{CD} 133+}$ cells to bone suggests that CSCs may preferentially interact with specific cells in the bone microenvironment, and the most likely candidates are osteoclasts that cause an increase in bone lysis at sites of bone metastases, as demonstrated by histomorphometric evidence.

With respect to clinical applications, CD133 may serve as a candidate marker to detect bone metastasis risk in patients with PC. The inability to predict development of metastatic disease in patients is a major challenge in PC management and has resulted in excessive therapy in some patients and delayed or insufficient therapy in others (25). The nature of the association between circulating tumor cells and bone metastasis remains controversial. The presence of circulating PC cells in the blood is an indication of dissemination of tumor cells from the primary site. Only a subset of circulating tumor cells may possess the necessary properties to target bone.

In light of the significant progress in the field of metastasis and stem cell research, we suggest a CSC-based model for bone metastasis in PC. CD133 regulates CSC and EMT properties in PC and sustains acquisition of osteolytic features through MIF secretion. These data demonstrate the role of EMT and CSCs in cancer metastasis to the bone. Thus, our findings may facilitate development of a novel classification system and therapeutic strategies for bone metastasis.

\section{Acknowledgements}

\section{Not applicable.}

\section{Funding}

The present study was supported by the Basic Science Research Program through the National Research Foundation of Korea, funded by the Ministry of Education (grant no. 2017R1D1A1A02018589), and by the Clinical Medicine Research Institute of the Chosun University Hospital (2015).

\section{Availability of data and materials}

All data generated or analyzed during the present study are included in this published article.

\section{Authors' contributions}

HS, BK, MP, YKo, YM, BJ, JS, YKi and WL take responsibility for the integrity of the data analysis. HS, BK, MP, YKo, YM, BJ and WL performed the experiments. HS and $\mathrm{BK}$ reviewed, analyzed, and interpreted the data. JS and YKi performed additional experiments. HS, BK and WL wrote the paper. All authors discussed the results and commented on the manuscript.

\section{Ethics approval and consent to participate}

All experimental procedures involving animals were performed in compliance with institutional and governmental requirements and were approved by the Institutional Animal Care and Use Committee (approval no. CIACUC2015-A0032), Chosun University, Gwangju, Korea.

\section{Patient consent for publication}

Not applicable. 


\section{Competing interests}

The authors declare that they have no competing interests.

\section{References}

1. Hassanipour-Azgomi S, Mohammadian-Hafshejani A, Ghoncheh M, Towhidi F, Jamehshorani S and Salehiniya H: Incidence and mortality of prostate cancer and their relationship with the Human Development Index worldwide. Prostate Int 4 $118-124,2016$.

2. Jemal A, Siegel R, Xu J and Ward E: Cancer statistics, 2010. CA Cancer J Clin 60: 277-300, 2010.

3. Jin JK, Dayyani F and Gallick GE: Steps in prostate cancer progression that lead to bone metastasis. Int J Cancer 128 : 2545-2561, 2011

4. NakazawaMand KyprianouN:Epithelial-mesenchymal-transition regulators in prostate cancer: Androgens and beyond. J Steroid Biochem Mol Biol 166: 84-90, 2017.

5. Chen YS, Wu MJ, Huang CY, Lin SC, Chuang TH, Yu CC and Lo JF: CD133/Src axis mediates tumor initiating property and epithelial-mesenchymal transition of head and neck cancer. PLoS One 6: e28053, 2011.

6. Al-Hajj M, Wicha MS, Benito-Hernandez A, Morrison SJ and Clarke MF: Prospective identification of tumorigenic breast cancer cells. Proc Natl Acad Sci USA 100: 3983-3988, 2003.

7. Shiozawa Y, Berry JE, Eber MR, Jung Y, Yumoto K, Cackowski FC, Yoon HJ, Parsana P, Mehra R, Wang J, et al: The marrow niche controls the cancer stem cell phenotype of disseminated prostate cancer. Oncotarget 7: 41217-41232, 2016.

8. Klonisch T, Wiechec E, Hombach-Klonisch S, Ande SR Wesselborg S, Schulze-Osthoff K and Los M: Cancer stem cell markers in common cancers-therapeutic implications. Trends Mol Med 14: 450-460, 2008.

9. Yu C, Yao Z, Jiang Y and Keller ET: Prostate cancer stem cell biology. Minerva Urol Nefrol 64: 19-33, 2012.

10. Kryczek I, Liu S, Roh M, Vatan L, Szeliga W, Wei S, Banerjee M, Mao Y, Kotarski J, Wicha MS, et al: Expression of aldehyde dehydrogenase and CD133 defines ovarian cancer stem cells. Int J Cancer 130: 29-39, 2012.

11. Colombel M, Eaton CL, Hamdy F, Ricci E, van der Pluijm G, Cecchini M, Mege-Lechevallier F, Clezardin P and Thalmann G: Increased expression of putative cancer stem cell markers in primary prostate cancer is associated with progression of bone metastases. Prostate 72: 713-720, 2012.

12. Shmelkov SV, St Clair R, Lyden D and Rafii S: AC133/CD133/ Prominin-1. Int J Biochem Cell Biol 37: 715-719, 2005.

13. Major AG, Pitty LP and Farah CS: Cancer stem cell markers in head and neck squamous cell carcinoma. Stem Cells Int 2013: 319489, 2013.
14. Collins AT, Berry PA, Hyde C, Stower MJ and Maitland NJ: Prospective identification of tumorigenic prostate cancer stem cells. Cancer Res 65: 10946-10951, 2005.

15. Moon Y, Kim D, Sohn H and Lim W: Effect of CD133 overexpression on the epithelial-to-mesenchymal transition in oral cancer cell lines. Clin Exp Metastasis 33: 487-496, 2016.

16. Sanchez-Tillo E, de Barrios O, Siles L, Cuatrecasas M, Castells A and Postigo A: $\beta$-catenin/TCF4 complex induces the epithelial-to-mesenchymal transition (EMT)-activator ZEB1 to regulate tumor invasiveness. Proc Natl Acad Sci USA 108: 19204-19209, 2011.

17. Arguello F, Baggs RB and Frantz CN: A murine model of experimental metastasis to bone and bone marrow. Cancer Res 48 6876-6881, 1988.

18. Valta MP, Tuomela J, Bjartell A, Valve E, Väänänen HK and Härkönen P: FGF-8 is involved in bone metastasis of prostate cancer. Int J Cancer 123: 22-31, 2008.

19. Lee KH, Ahn EJ, Oh SJ, Kim O, Joo YE, Bae JA, Yoon S, Ryu HH, Jung S and Kim KK: KITENIN promotes glioma invasiveness and progression, associated with the induction of EMT and stemness markers. Oncotarget 6: 3240-3253, 2015.

20. Xu MH, Gao X, Luo D, Zhou XD, Xiong W and Liu GX: EMT and acquisition of stem cell-like properties are involved in spontaneous formation of tumorigenic hybrids between lung cancer and bone marrow-derived mesenchymal stem cells. PLoS One 9: e87893, 2014.

21. Dai J, Hensel J, Wang N, Kruithof-de Julio M and Shiozawa Y: Mouse models for studying prostate cancer bone metastasis. Bonekey Rep 5: 777, 2016.

22. Pasqualon T, Lue H, Groening S, Pruessmeyer J, Jahr H, Denecke B, Bernhagen J and Ludwig A: Cell surface syndecan-1 contributes to binding and function of macrophage migration inhibitory factor (MIF) on epithelial tumor cells. Biochim Biophys Acta 1863: 717-726, 2016.

23. Madeira MF, Queiroz-Junior CM, Costa GM, Santos PC, Silveira EM, Garlet GP, Cisalpino PS, Teixeira MM, Silva TA and Souza Dda G: MIF induces osteoclast differentiation and contributes to progression of periodontal disease in mice. Microbes Infect 14: 198-206, 2012.

24. Movila A, Ishii T, Albassam A, Wisitrasameewong W, Howait M, Yamaguchi T, Ruiz-Torruella M, Bahammam L, Nishimura K, Van Dyke T and Kawai T: Macrophage migration inhibitory factor (MIF) supports homing of osteoclast precursors to peripheral osteolytic lesions. J Bone Miner Res 31: 1688-1700, 2016.

25. Chu K, Cheng CJ, Ye X, Lee YC, Zurita AJ, Chen DT, Yu-Lee LY, Zhang S, Yeh ET, Hu MC, et al: Cadherin-11 promotes the metastasis of prostate cancer cells to bone. Mol Cancer Res 6: 1259-1267, 2008.

This work is licensed under a Creative Commons Attribution-NonCommercial-NoDerivatives 4.0 International (CC BY-NC-ND 4.0) License. 